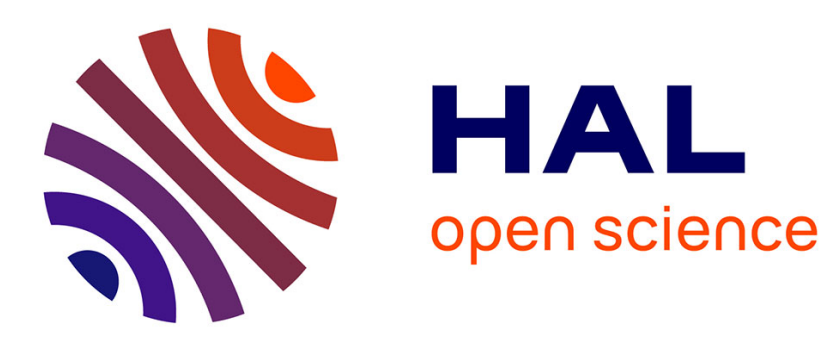

\title{
Imaging electric and magnetic near field of radiating structures by infrared thermography
}

Daniel Prost, François Issac, Maxime Romier

\section{To cite this version:}

Daniel Prost, François Issac, Maxime Romier. Imaging electric and magnetic near field of radiating structures by infrared thermography. EMC Europe 2019, Sep 2019, BARCELONE, Spain. hal02364926

\section{HAL Id: hal-02364926 \\ https://hal.science/hal-02364926}

Submitted on 15 Nov 2019

HAL is a multi-disciplinary open access archive for the deposit and dissemination of scientific research documents, whether they are published or not. The documents may come from teaching and research institutions in France or abroad, or from public or private research centers.
L'archive ouverte pluridisciplinaire HAL, est destinée au dépôt et à la diffusion de documents scientifiques de niveau recherche, publiés ou non, émanant des établissements d'enseignement et de recherche français ou étrangers, des laboratoires publics ou privés. 


\section{Imaging electric and magnetic near field of radiating structures by infrared thermography}

\author{
Daniel Prost \\ ONERA/DEMR \\ Université de Toulouse \\ F-31055 Toulouse, France \\ daniel.prost@onera.fr
}

\author{
François Issac \\ ONERA/DEMR \\ Université de Toulouse \\ F-31055 Toulouse, France \\ francois.issac@onera.fr
}

\author{
Maxime Romier \\ CNES \\ The French Space Agency \\ Toulouse, France \\ maxime.romier@cnes.fr
}

\begin{abstract}
The characterization and visualization of the radiated electromagnetic field is a way to diagnose and check microwaves sources, in particular in the space industry. Beyond the traditional 3D scanning of the radiating element, infrared thermography is an alternative way that may give key results in a reduced time, since a few seconds are sufficient to obtain the emitted field map even for a complex multi-cells antenna. This method, called EMIR (ElectroMagnetic InfraRed) has been developed and used for years at ONERA. We have recently extended this technique to the magnetic field, which will lead to a complete characterization of the near field structure. We illustrate this feature in the particular cases of antennas for space application and for a High Impedance Surface (HIS), a metamaterial structure that could be used to reduce the coupling between antennas confined in compact structures (typically size constraints of the spatial components).
\end{abstract}

Keywords-Electromagnetism, Infrared thermography, High Impedance Surface, Near-field visualization.

\section{INTRODUCTION}

The electromagnetic infrared $\left(\mathrm{EMIR}^{\mathrm{TM}}\right)$ method has been developed and used at ONERA [1] in order to visualize and measure microwave electric fields. This method consists in inserting specific conductive thin films in the microwave electric field to be measured. Because of the low electrical resistivity of the film, induced electric currents generate ohmic losses inside and induce a heating which is recorded by the infrared camera. The measured increase of temperature is post-processed to evaluate the incident microwave electric field. It is also possible to measure the magnetic component of the wave when the field structure is not a plane wave (typically in the near-filed zone): in this case, a thin ferromagnetic film is used and ferromagnetic losses also initiate a heating captured by the camera $[2,3]$.

We present here some recent measurements achieved on components that are likely to be used in space systems. The EMIR $^{\mathrm{TM}}$ method may be very useful for rapidly characterizing and diagnosing array antennas or other components (like metasurface) for space industry, which is becoming a hot topic in the context of growing production of much smaller satellites. The EMIR ${ }^{\mathrm{TM}}$ method is also well suited to provide experimentally 2D field representations in an original, fast and convenient way.

We present in this paper near-field measurement results of two different antennas: a $\mathrm{Ku} / \mathrm{Ka}$-band horn antenna (section III), and a multibeam antenna. Such devices are more and more used on communication satellites (section IV). In the section $\mathrm{V}$ we provide images of both electric and magnetic near field of a High Impedance Surface (HIS) developed at ONERA. To our knowledge, these are the first experimental visualizations of both electric and magnetic field of a metamaterial structure.

\section{EMIR METHOD OF MEASUREMENT}

The EMIR measurement is illustrated by Fig. 1.

For electric field measurement, the conductive film is a carbon loaded polyamide with a surface impedance $Z_{s}$ of almost $2 \mathrm{k} \Omega / \mathrm{sq}\left(Z_{s}\right.$ is the resistance per square, $Z_{s}=1 /(\sigma \mathrm{e})$ where $\sigma$ is the conductivity and $\mathrm{e}$ the thickness of the film). The absorbed power ratio is estimated at almost $15 \%$, which is sufficient to obtain field patterns, still low enough to avoid modifying the electric field structure.

- For the magnetic field measurement, the sensing film is a $25-\mu \mathrm{m}$ thick commercial FLEX-TOKIN composed of ferromagnetic micro pellets embedded in a polymer matrix. The magnetic losses are proportional to the imaginary part of the relative permeability which is evaluated to 100 in our frequency range (1 to $2 \mathrm{GHz}$ ).

The incident EM field is radiated by the component under test structure (antenna or HIS) fed by a RF amplifier properly driven by a signal generator providing a low frequency modulation; camera recordings are then demodulated at the same low frequency which suppresses convective heating noise and other continuous components of the heating. A few Watts injected on the radiated element allows to get a few degrees heating dynamic recorded by the camera.

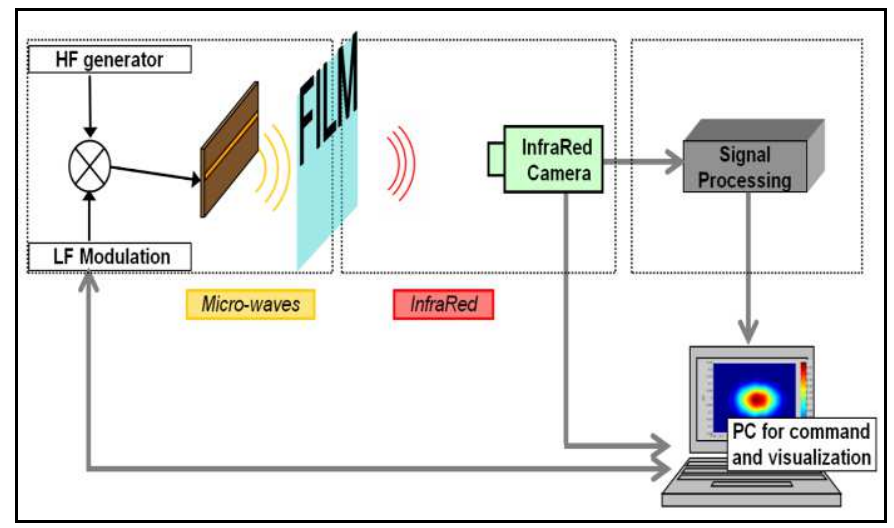

Fig. 1: The EMIR method: the fed component (antenna or else) radiates and heats the film; the infrared camera records this heating in which convection part is eliminated through low frequency modulation 
After having registered the demodulated heating, we can deduce the field amplitude. Indeed the thermal frames are related to the amplitude of the electric or magnetic field since we have:

In the case of the electric field (Kapton film):

$$
\left|E^{\prime}\right|=\bar{\kappa}_{R} \sqrt{\Delta r_{\text {nu }}}
$$

- $\quad$ In the case of the magnetic field (Tokin film):

$$
|H|=k_{H} \sqrt{\Delta T_{\text {avg }}}
$$

Where $\mathrm{k}_{\mathrm{E}}$ and $\mathrm{k}_{\mathrm{H}}$ are coefficients that depend on the heat transfer coefficient, the heat capacity, the density of the film, and the modulation frequency.

Therefore we can derive from equations (1) and (2) the electric or magnetic field amplitude as a function of the heating through a factor that depends only on film characteristics and modulation frequency. These factors can be considered as calibration factors depending on the parameters above. However, and more directly (without calibration), raw thermal frames can be interpreted as nonnormalized electromagnetic power density images (normalization not mandatory for getting relative power information through a dB scale).

\section{KU-BAND HORN ANTENNA SOURCE}

This $\mathrm{Ku} / \mathrm{Ka}$-band spline-profiled square horn antenna has been designed for space application [4], is linearly polarized. It has been conveniently used to monitor the influence of the thin film on return losses. When the aperture is "sealed" by the film (worst case), mismatches remain below $-10 \mathrm{~dB}$.

Obtaining the electric field thermal frame takes a few seconds; any major defect can easily be detected without any signal processing. This appears clearly on the heating images, as illustrated by the Fig. 2 .

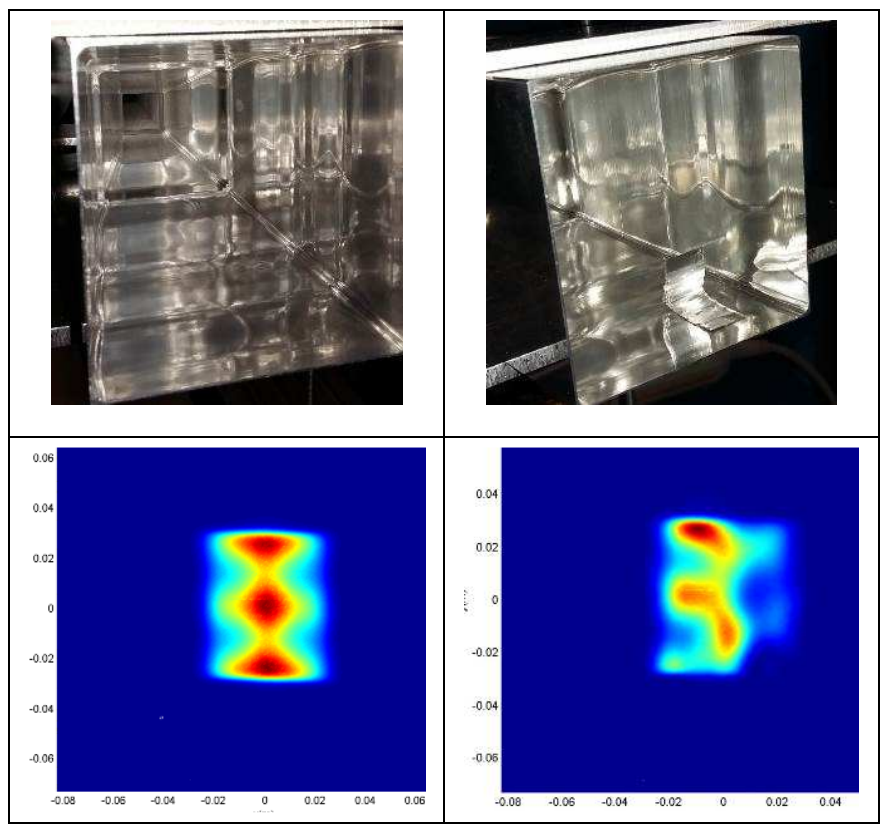

Fig. 2: Ku-band horn antenna near electric field at $12 \mathrm{GHz}$, without and with an insertion defect

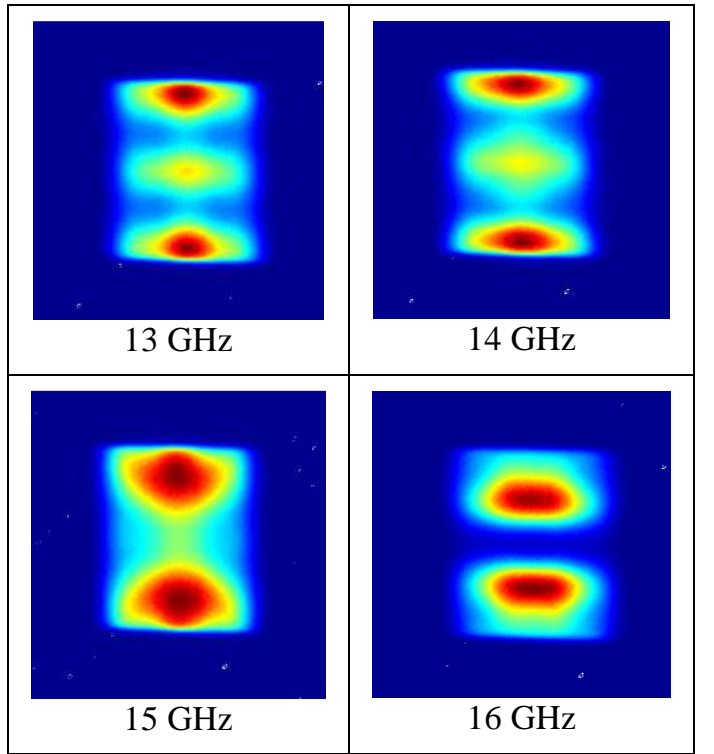

Fig. 3: Near-field (Electrical) frames at the aperture of the horn antenna vs frequency

Thermal frames can be produced at different distances and/or at different frequencies to obtain general information on the antenna behavior. For instance the Fig. 3 shows how the emission mode evolves as frequency increases.

\section{MULTIPLE FEED PER BEAM FOCAL ARRAY}

The Multiple Feed per Beam focal array [5] is circularly polarized and has been designed for space applications in Ka-band. Its geometry is illustrated by the Fig. 4 below:

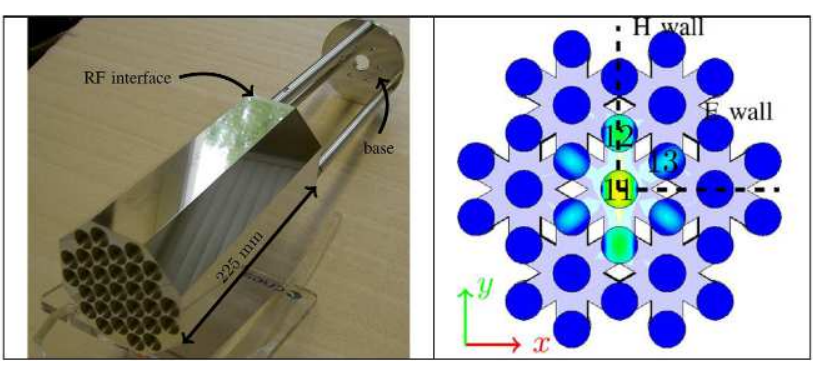

Fig. 4: Multiple Feed per Beam focal array, and computed E field amplitude for a TE11 mode

In our measurement setup, the focal array is fed via the central waveguide by a circularly polarized TE11 mode (more details in [5]). Because of slot coupling, RF power is distributed to a sub-array of 7 feed horn. Fig. 5 (left) provides heating measurement at $3 \mathrm{~mm}$ above the antenna aperture. To maximize image contrast, it is worth normalizing the heating to its peak value; we obtain the power density $\mathrm{P}(\mathrm{x}, \mathrm{y})$ in $\mathrm{dB}$, on Fig. 5 (right), with :

$$
\mathrm{P}(\mathrm{x}, \mathrm{y})=10 \cdot \log (\Delta \mathrm{T}(\mathrm{x}, \mathrm{y}) / \Delta \mathrm{T} \max )
$$




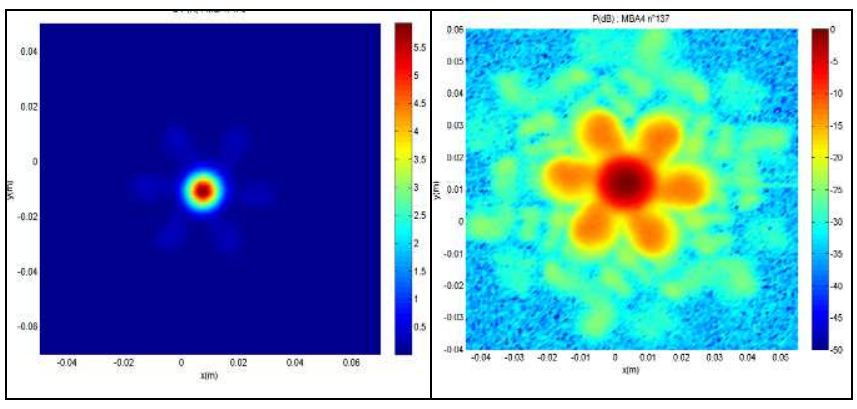

Fig. 5: Heating image of the MFB source (at $3 \mathrm{~mm}$ of the radiating surface), and related power density in $\mathrm{dB}$

We achieved measurements at different distances from $1 \mathrm{~mm}$ to a few wavelengths $(50 \mathrm{~mm}$ corresponding to 3 wavelengths). As a validation process, in Fig. 6 we present measurement and simulation results, for 2 distances ( 3 and $30 \mathrm{~mm}$ ). The simulations have been computed with CST MWS using the time domain solver. The depicted distribution shows time-averaged squared amplitude of the tangential electric field.

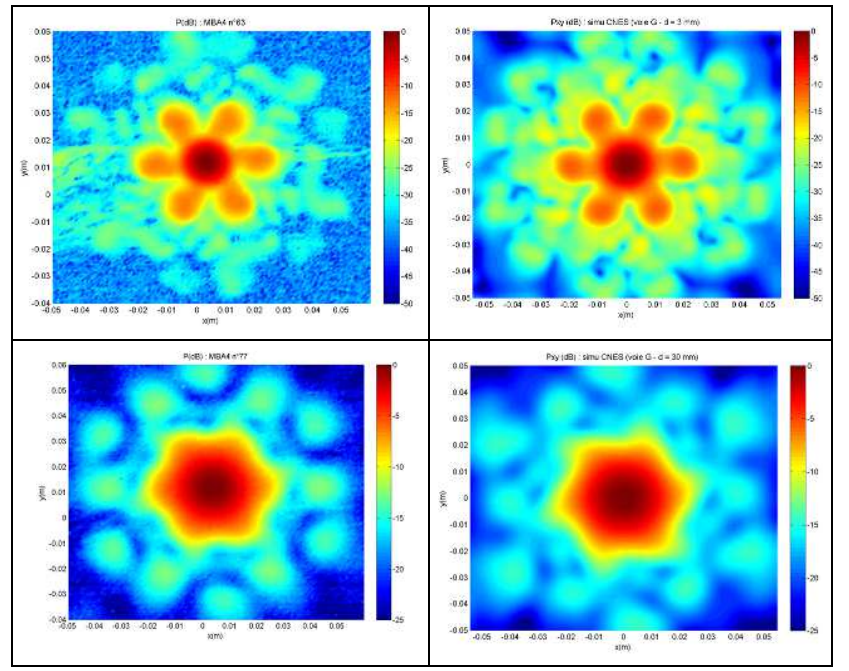

Fig. 6: Power density at 3 (up) and $30 \mathrm{~mm}$ (bottom) ; measurement on left, simulation on right

The noticeable agreement between the two pictures, although the presence of the film was not accounted in the simulation, confirms its low intrusive behavior. A slight "twist" of the pattern can be observed, which direction switches when the polarization is changed: indeed we have observed that behavior instantly by switching the beam polarization. Thus the thermal signature can detect relatively slight phenomena - through their impact on field amplitude such as field polarization, or unbalanced beamforming.

\section{High IMPEDANCE SURFACE (HIS)}

HIS is a special passive electromagnetic structure (based on metamaterial technology) designed for reducing mutual coupling between adjacent patch antennas (in particular for applications where size constraints are crucial; like space systems) [6].

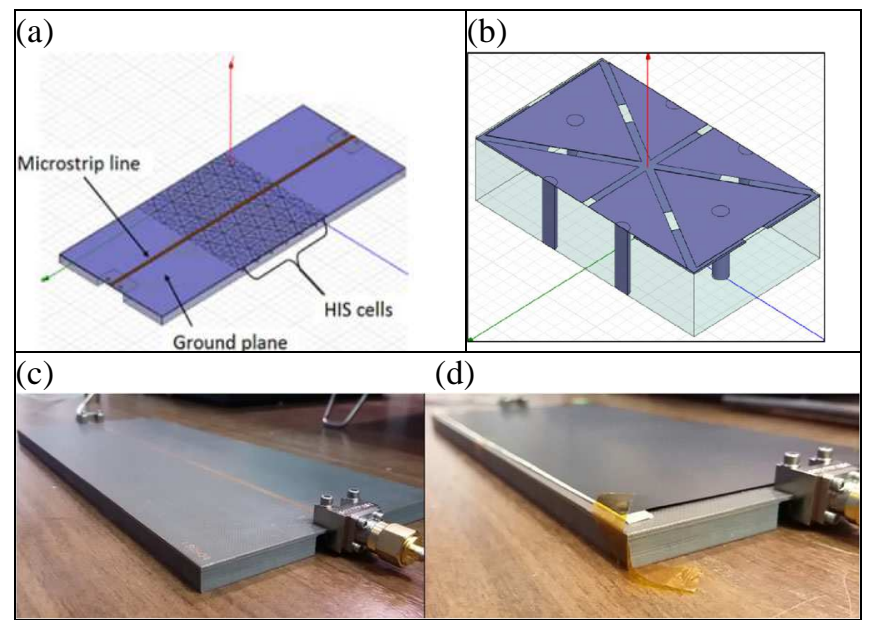

Fig. 7: Structure of the HIS embedded in the transmission line (a), elementary cell (b), picture of the realized structure (c), thin film implementation (d)

As illustrated by Fig. 7, the HIS cell consists of a two layers dielectric substrate with a first $4.8-\mathrm{mm}$ thick layer of TLY $\left(\varepsilon_{\mathrm{r}}=2.2\right)$ with ground plane on its bottom face. The second layer, $0.127-\mathrm{mm}$ thick, is made of the same material. A high capacitance value is obtained with coupled patches, which are printed on both sides of this thin dielectric substrate, to obtain a small unit cell (almost $11 \times 19 \mathrm{~mm}^{2}$ ). Triangular and hexagonal elements are designed for bottom and top patches respectively. Vertical vias in the triangle centers ensure the patch to ground plane connection and create the inductive effect. This HIS is therefore composed of periodic capacitive and inductive elements, which exhibit resonance frequencies, in particular around $2 \mathrm{GHz}$.

We fed our HIS with a microwave power (modulated at $0.2 \mathrm{~Hz}$ ) of the order of 2 to $3 \mathrm{~W}$. The HIS structure is connected to a $50 \Omega$ load.

Compared to previous measurements [7], we are now able to visualize both magnetic and electric field frames.

Indeed, using successively our electric and magnetic losses films, we visualize electric and magnetic field patterns of the HIS over a large frequency range ( 0.8 to $2.3 \mathrm{GHz})$. 


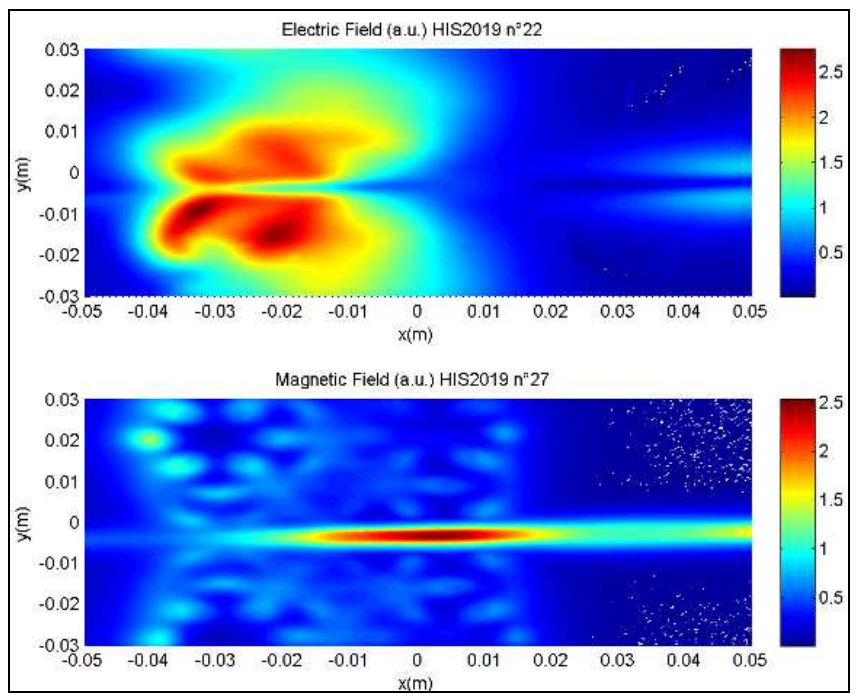

Fig. 8: Electric and magnetic near field at resonance frequency (2 GHz)

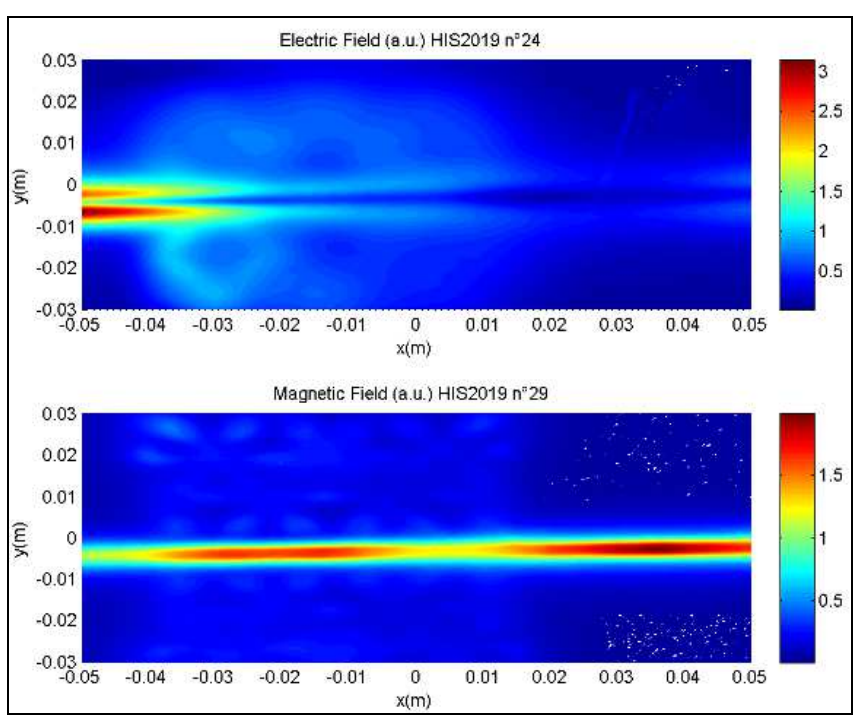

Fig. 9: Electric and magnetic near far from resonance frequency $(2.25 \mathrm{GHz})$

The last Fig. 8 and 9 are given in arbitrary units. These illustrate the differences of the near field structures between resonant $(2 \mathrm{GHz}$, Fig. 8) and passing $(2.25 \mathrm{GHz}$, Fig. 9) behaviors:

At $2 \mathrm{GHz}$ we observe the resonant behavior of the HIS cells. It can be noticed that geometric details appear: the current flowing on the triangular patches (Fig. 8) is exhibited by the magnetic field frame in particular. The thermography method could therefore be used as a diagnose tool.

At $2.25 \mathrm{GHz}$ the HIS exhibits passing behavior (Fig. 9) ; some details of the structure can still be distinguished, but of course much less current is present on the patches.

\section{CONCLUSION}

In conclusion, we have shown how the $\mathrm{EMIR}^{\mathrm{TM}}$ method could provide accurate and replicable radiation signatures, and highlight antenna behaviors as well as metamaterial structures almost instantly. More generally, it is also an experimental tool that provides 2D maps of the electric or magnetic fields that are usually only obtained by simulation. In the EMC context, it allows, in a low intrusive and fast way, to check RF behavior at different levels (antenna, system, integration -including detection electromagnetic leaks through small apertures) and gives 2D fields cartographies in a large frequency range.

\section{REFERENCES}

[1] P.Levesque, L.Leylekian, "Capteur vectoriel de champs électromgnétique par thermographie infrarouge”, French Patent $\mathrm{n}^{\circ} 9816079,1998$

[2] D. Prost, F. Issac, F. Lemaitre, J.P. Parmantier "Infrared Thermography of Microwave Electromagnetic Fields", D, EMC Europe, Rome, (2012)

[3] J.Vernieres, J.F. Bobo, D. Prost, F. Issac, F. Boust, "Ferromagnetic microstructured thin films with high complex permeability for microwave applications", J. of Appl. Phys. 109, 07A323, 2011.

[4] J.-P. Adam, P. Hamel, I. Albert, M. Romier, D. Belot, "Design, Manufacturing and Test of a Spline-Profile Square Horn for Focal Array Applications", 15th Int. Symposium on Antenna Technology and Applied Electromagnetism (ANTEM), 2012

[5] C. Leclerc, M. Romier, H.Aubert, A. Annabi, "Ka-Band Multiple Feed per Beam Focal Array Using Interleaved Couplers", IEEE Trans. Microwave Theory and Techniques, 62, n³, 2014

[6] N.Capet, "Amélioration du découplage inter élément par surface haute impédance pour antennes réseaux GNSS compactes », Ph.D. Report, Université de Toulouse, 2010 [in french]

[7] D.Prost, F.Issac, C.Martel, N.Capet, J.Sokoloff, O.Olivier, "Electric field imaging of a high impedance surface for GNSS array decoupling application”, Eur. Phys. J. Appl. Phys. (2015) 